\title{
Randomized Controlled Clinical Study to Compare the Effect of Intravenous Magnesium Sulphate versus Diclofenac Sodium as Postoperative Analgesic after Abdominal Hysterectomy under Original Article General Anaesthesia
}

\author{
Kareem A. Wahba, Mohamed E. Shawky, Marco R. Ramzy
}

Department of Gynecology and Obstetrics, Faculty of Medicine, Ain Shams University

\begin{abstract}
Background: The major goal in postoperative pain management is to minimize the dose of medications and decrease side effects while still providing adequate analgesia. Postoperative pain relief leads to earlier mobilization, shortened hospital staying, reduced hospital costs and increased patient satisfaction.

Aim of the study: To compare the effect of intravenous magnesium sulfate versus intravenous diclofenac on postoperative analgesia in patients undergoing total abdominal hysterectomy.

Patients and Methods: This single blinded randomized controlled clinical study was conducted on 60 patients who had undergone hysterectomy surgery in Ain-Shams University Maternity Hospital from October 2017 to July 2018. The patients were divided into two groups of 30 patients each based on a random number table; one receiving magnesium sulphate and the other receiving diclofenac.

Results: The mean age of the patients in group A was $49.97 \pm 5.31$ and it was $51.50 \pm 6.13$ in the study group B; there was no significant difference between them $(\mathrm{p}<0.05) \mathrm{p}=0.305$. The mean BMI of the patients in group A was $27.45 \pm 2.13 \mathrm{Kg} /$ $\mathrm{m}^{2}$ and it was $27.12 \pm 2.42 \mathrm{Kg} / \mathrm{m}^{2}$ in group B i.e., there was no significant difference between them $(\mathrm{p}<0.05 \mathrm{p}=0.470)$. Also, the duration of surgery of all the patients was recorded; the mean duration of surgery of group A was $104.77 \pm 8.51$ and that of group B was $102.90 \pm 10.17$ with $\mathrm{p}$ value $=0.444$.

Conclusion: IV preventive doses (low doses) of magnesium sulphate with dosage of $50 \mathrm{mg} / \mathrm{kg}$ in $100 \mathrm{~mL}$ of normal saline solution alleviate postoperative pain throughout the first day after TAH under balanced general anesthesia significantly and reduce opioid consumption as well.
\end{abstract}

Key Words: Intravenous magnesium sulphate, diclofenac sodium, postoperative analgesic, abdominal hysterectomy, general anaesthesia

Received: 23 May 2019, Accepted: 22 June 2019

Corresponding Author: Marco Ramzy, MD, Department of Gynecology and Obstetrics, Faculty of Medicine, Ain Shams University, Egypt, Tel.: +2 01222739307, E-mail: dr.marco@live.com

ISSN: 2090-7265, August 2019, Vol. 9, No. 3

\section{INTRODUCTION}

Hysterectomy is the most common major gynaecological operation and the second most common gynaecologic surgery done after caesarean section all over the world ${ }^{[1]}$.

Abdominal hysterectomy is associated with postoperative pain. Traditional methods for postoperative pain management included opioids administered systemically using patient-controlled intravenous analgesia (PCA) or neuroaxially via epidural or spinal injections. However, pain relief, specifically on movement, is not always adequately controlled when using PCA, despite moderate to large doses of morphine. This is associated with side-effects such as postoperative nausea and vomiting (PONV), tiredness, pruritus, headache and constipation ${ }^{[2]}$.
The major goal in postoperative pain management is to minimize the dose of medications and decrease side effects, while still providing adequate analgesia. Postoperative pain relief leads to earlier mobilization, shortened hospital staying, reduced hospital costs and increased patient satisfaction $^{[3]}$.

Narcotics are the most common analgesics which are used after the surgeries. But physicians are always looking for replaceable methods with fewer side effects and cost, one of the intravenous adjuvant that has been shown potential in analgesia is magnesium sulfate ${ }^{[4]}$.

The mechanism of the analgesic effect of magnesium is not clear but interference with calcium channels and $\mathrm{N}$-methyl-D-aspartate (NMDA) receptor seem to play an important role ${ }^{[5]}$. 
As there are no studies in our region, up to our knowledge, to compare the effect of both magnesium sulphate and diclofenac as analgesic in post hysterectomy patients, we will do this one.

\section{AIM OF THE WORK}

To compare the effect of intravenous magnesium sulfate versus intravenous diclofenac on postoperative analgesia in patients undergoing total abdominal hysterectomy.

\section{PATIENTS AND METHODS}

\section{Study design:}

The study was a single blinded randomized controlled clinical trial.

\section{Site of the study:}

The study was conducted in Ain Shams University Maternity Hospital from October 2017 to July 2018.

\section{Study population:}

Sixty women were recruited in the study that was planned to undergo abdominal hysterectomy fulfilling the following criteria:

\section{Inclusion criteria:}

- Age: 40 - 60 years old.

- Body mass index (BMI):20-30 kgm/ $/ \mathrm{m}^{2}$.

- Elective surgery: All causes of abnormal benign uterine bleeding e.g (dysfunctional uterine bleeding, fibroid uterus, adenomyosis. etc)

- Size of uterus: Uterus size below the umbilicus (fundal level less than 24 weeks gestation).

- Type of operation: Total or subtotal hysterectomy with or without salpingo-oophrectomy using a transverse lower abdominal incision.

- Time of surgery: Total time of surgery from induction of anesthesia till end of surgery was less than 2 hours.

\section{Exclusion criteria:}

- Age: below 40 years and above 60 years old.

- BMI: $<20$ or $>30 \mathrm{Kgm} / \mathrm{m}^{2}$

- Patients who were suspicious for or diagnosed as malignancy.
- Uterine size above the umbilicus (above 24 weeks gestation by fundal level).

- Patients who were planned to be incised by midline laparotomy or whom will undergo concomitant other surgery e.g. (hernia, abdominoplasty).

- Patients who were known to have chronic end organ disease or disease affecting pain perception as diabetes mellitus, cardiac diseases, chronic renal diseases, rheumatoid diseases.

- Time of operation exceeded 2 hours.

- Allergy to any of the drugs that were used in the study.

- Patients who refused to do the operation under general anaesthesia.

All participants were counseled and asked to give a written informed consent.

All patients of the two groups were submitted to the following:

\section{Complete history taking:}

- Personal history (name, age, marital status, special habits).

- Detailed history of present illness (onset, course, duration of uterine bleeding).

- Any associated gynecological symptoms as dysmenorrhea, dyschezia, dyspareunia, postmenopausal symptoms.

- Any past history of chronic diseases as hypertension, diabetes mellitus and cardiac disease.

- Family history of the same condition or history of tumors running in the family.

\section{Pre operative assessment}

\section{General examination:}

- Vital data: blood pressure, pulse, body temperature and respiratory rate, pallor, chest and heart auscultation, lower limb edema and varicose veins.

\section{Abdominal examination:}

- Uterine level: below the umbilicus.

- Uterus mobilization on examination.

- Previous scar: previous laparotomy. 
- Abdominal tenderness: any sign of acute abdomen e.g. (complicated ovarian cyst or complicated fibroid).

- Any associated diseases e.g: hernia (umbilical or incisional).

\section{Local examination:}

- Inspection: for any vaginal infections or genital organ prolapse.

- Speculum examination: for any cervical ulcers or any genital infections.

- Bimanual vaginal examination: to assess the uterine fundal level, mobility and symmetry, also to examine the adenexae for any associated cysts or malignancy.

\section{Investigations:}

Laboratory: complete blood picture, liver profile, kidney profile, fasting and 2 hours post prandial glucose test, coagulation profile, urine analysis and viral markers.

Ultrasound: for the size of the uterus, endometrial thickness, fibroids number and size of fibroids, adenexae and any associated pathology as cysts or masses.

\section{Methodology}

\section{Randomization:}

All the patients were assigned to the study distributed to the two groups randomly according to the randomization table below which was done using computer graphed software.

\section{Allocation:}

Sealed opaque sequentially numbered envelopes that contained the number of the patient (from zero to sixty) were placed in a box from which an envelope can be drawn at the recovery room immediately post operative, after that the patient was given her own drug according to the randomization table, which was shown on table (1).

\section{Blinding:}

According to the study design, the patients were only blind to the drug, but the service provider was informed by the drug according to number distribution of the drug by the randomization table.

\section{Intervention:}

Sixty Patients were randomly enrolled to one of the two groups (30 patients each) according to the randomization table. The magnesium group (group A) received $50 \mathrm{mg} / \mathrm{kg}$ of magnesium sulfate in $100 \mathrm{~mL}$ of normal saline solution (isotonic saline) just 15 to 30 minutes post operative, whereas patients in diclofenac group (group B) received $75 \mathrm{mg}$ of diclofenac sodium in $100 \mathrm{~mL}$ of $0.9 \%$ sodium chloride solution at the same time post operatively.

In this clinical trial, patients were blinded to the drug; the name of the drug was put in an envelope and was opened immediately post operative directly before giving it to the patient. All patients received a balanced general anesthesia, duration of surgeries did not exceed 2 hours; so there was no more fluid loss, wasting time or abdominal stimulation. After the operation, patients transferred to the recovery room. The consciousness and the vital signs were evaluated until they were ready to be discharged from there. Heart rate and non invasive blood pressure were recorded over 24 hours after the surgeries at (zero, 1, 6, 12, 18, 24) hours.

All patients involved in this trial were informed about the symptoms of magnesium sulfate toxicity which are nausea, vomiting, flushing of skin, muscle weakness and facial paresthesia.

The VAS score was recorded at emergence of anesthesia and every one hour for 24 hours after the surgery. Demographic data (age, BMI), duration of the surgery and pethidine consumption were recorded over 24 hours after the surgeries exactly. According to the decision of Ethical Committee, pethidine was administered in case of VAS > 3 and the total amounts of pethidine used by the patients in the two groups was calculated in the first 24 hours post-operative. The dose of rescue analgesia is $1 \mathrm{mg} / \mathrm{kg}$, not to be repeated more than 3 times in the first 24 hours post operative as well as post-operative vomiting attacks were monitored and recorded by the number of patients developed vomiting in each group.

Also, we recorded the time of regaining intestinal motility (by hours) by the patients of the two groups post operative

\section{Outcomes and data collection}

\section{Primary outcome:}

Study the effect of magnesium sulphate as analgesic after abdominal hysterectomy by calculation of the total amount of pethidine in milli grams $/ \mathrm{kg}$ in the first 24 hours post operative.

\section{Secondary outcome:}

1. Time of first dose of pethidine needed as rescue analgesic post operative.

2. Duration of hospital stay post operatively in hours.

3. Time of regaining of intestinal motility by assessment of the intestinal sounds every hour post operatively. 
4. Occurrence of vomiting by the patients in the first 24 hours post operative.

\section{Ethical and legal aspects:}

Before being admitted to the clinical study, the patient was consented after knowing the nature, scope and possible consequences of the clinical study.

An informed Arabic consent document in understandable way was obtained from all the patients prior screening and enrollment.

Sample size: was calculated using PASS* version 11 program, setting the type- 1 error (alpha) at 0.05 and the power (1-beta) at 0.8. According to Taheri et al. (2015), the mean pain score among magnesium sulphate was $4.6 \pm 0.9$ and it was $5.9 \pm 0.45$ among the placebo group. Assuming that among (NSAIDS), the pain score is $5.3 \pm 0.45$. Calculation according to these values produced a minimal sample size of 30 cases per each group.

\section{Statistical methods:}

Statistical presentation and analysis of the present study was conducted using the mean, standard Deviation, unpaired student t-test and chi-square tests by SPSS V20.

Unpaired Student T-test was used to compare between two groups in quantitative data.

Chi-square, the hypothesis that the row and column variables are independent without indicating strength or direction of the relationship. Pearson chi-square and likelihood-ratio chi-square, Fisher's exact test and Yates' corrected chi-square are computed for $2 \times 2$ tables.

$>0.05$ Non significant $<0.05^{*}$ significant $<0.001^{* *}$ High significant.

\section{RESULTS}

Table 1: Age, BMI and duration of surgery of the two groups.

\begin{tabular}{|c|c|c|c|c|c|c|c|c|}
\hline & \multicolumn{3}{|c|}{$\begin{array}{c}\text { Group A } \\
(\mathrm{N}=30)\end{array}$} & \multicolumn{3}{|c|}{$\begin{array}{c}\text { Group B } \\
(\mathrm{N}=30)\end{array}$} & \multicolumn{2}{|c|}{ T-test } \\
\hline & Mean & \pm & $\mathrm{SD}$ & Mean & \pm & SD & $\mathrm{T}$ & P-value \\
\hline Age (years) & 49.97 & \pm & 5.31 & 51.50 & \pm & 6.13 & 1.036 & 0.305 \\
\hline BMI $(\mathrm{Kg} / \mathrm{m} 2)$ & 27.45 & \pm & 2.13 & 27.12 & \pm & 2.42 & 0.724 & 0.470 \\
\hline Duration of surgery (min.) & 104.77 & \pm & 8.51 & 102.90 & \pm & 10.17 & 0.771 & 0.444 \\
\hline
\end{tabular}

Table 1 showed that there was no significant statistical difference between the two groups regarding age, BMI and duration of surgery of the two groups.

The mean blood pressure recorded showed no significant difference except that of the first hour postoperative.
The mean blood pressure after one hour of group A was $72.08 \pm 5.78$ and that for group B was $75.82 \pm 5.96$ with $P$-value $=0.016$; while the $P$-values of the mean blood pressure at $(0,6,12,18,24)$ hours postoperative was 0.447 , $0.668,0.362,0.683,0.977$, respectively, as shown in (Table 2).

Table 2: Mean blood pressure in $\mathrm{mm} / \mathrm{Hg}$.

\begin{tabular}{|c|c|c|c|c|c|c|c|c|}
\hline \multirow{2}{*}{ Mean BP $(\mathrm{mm} / \mathrm{Hg})$} & \multicolumn{3}{|c|}{ Group A } & \multicolumn{3}{|c|}{ Group B } & \multicolumn{2}{|c|}{ T-test } \\
\hline & Mean & \pm & $\mathrm{SD}$ & Mean & \pm & $\mathrm{SD}$ & $\mathrm{t}$ & $P$-value \\
\hline Zero time post op. & 74.67 & \pm & 5.54 & 75.27 & \pm & 5.73 & 0.766 & 0.447 \\
\hline After 1hour & 72.08 & \pm & 5.78 & 75.82 & \pm & 5.96 & 2.467 & $0.016^{*}$ \\
\hline After $6 \mathrm{hrs}$. & 74.54 & \pm & 5.35 & 75.16 & \pm & 5.81 & 0.430 & 0.668 \\
\hline After $12 \mathrm{hrs}$. & 73.75 & \pm & 5.42 & 75.05 & \pm & 5.54 & 0.919 & 0.362 \\
\hline After $18 \mathrm{hrs}$. & 73.87 & \pm & 5.16 & 74.44 & \pm & 5.62 & 0.409 & 0.683 \\
\hline After $24 \mathrm{hrs}$. & 75.08 & \pm & 5.90 & 75.12 & \pm & 5.00 & 0.028 & 0.977 \\
\hline
\end{tabular}

$\mathrm{t}$ test $\quad$ data are presented as mean $\pm \mathrm{SD}$ or number $\quad \mathrm{n}=$ number of patients.


Table 3 showed no statistical significance between group A and B except at one hour post operative.

The pain experienced by the patients was measured based on the VAS score every hour over the first 24 hours after surgery on the basis of the t-test as shown in (Table 3) and figure 6. The data indicated that the mean pain was significantly different between the two groups at most measured time points being lesser at group A than group B.

Table 3: Pain scoring if the patients according to the visual analogue score (VAS).

\begin{tabular}{ccccccccc}
\hline \multirow{2}{*}{ Pain scoring bu (VAS) } & \multicolumn{3}{c}{ Group A } & \multicolumn{3}{c}{ Group B } & \multicolumn{2}{c}{ T-test } \\
\cline { 2 - 8 } & Mean & \pm & SD & Mean & \pm & SD & T & $P$-value \\
\hline 1 & 0.0 & \pm & 0.00 & 1.0 & \pm & 0.2 & - & - \\
2 & 0.0 & \pm & 0.00 & 1.0 & \pm & 0.4 & - & - \\
3 & 1.0 & \pm & 0.20 & 3.1 & \pm & 0.5 & 21.359 & $<0.001^{*}$ \\
4 & 2.0 & \pm & 0.53 & 1.0 & \pm & 0.5 & 7.517 & $<0.001^{*}$ \\
5 & 3.0 & \pm & 0.50 & 2.3 & \pm & 0.3 & 6.575 & $<0.001^{*}$ \\
6 & 2.6 & \pm & 0.70 & 2.2 & \pm & 0.5 & 2.547 & $0.014^{*}$ \\
7 & 1.2 & \pm & 0.12 & 2.0 & \pm & 0.7 & 6.170 & $<0.001^{*}$ \\
8 & 1.0 & \pm & 0.30 & 3.0 & \pm & 0.5 & 18.787 & $<0.001^{*}$ \\
9 & 1.4 & \pm & 0.50 & 1.2 & \pm & 0.2 & 2.034 & $0.046^{*}$ \\
10 & 2.2 & \pm & 1.00 & 1.1 & \pm & 0.3 & 5.771 & $<0.001^{*}$ \\
11 & 3.0 & \pm & 0.5 & 2.6 & \pm & 0.7 & 2.547 & $0.015^{*}$ \\
12 & 2.0 & \pm & 0.2 & 1.5 & \pm & 1.0 & 2.685 & $0.009^{*}$ \\
13 & 1.3 & \pm & 0.6 & 3.0 & \pm & 1.1 & 7.431 & $<0.001^{*}$ \\
14 & 1.9 & \pm & 1.0 & 1.4 & \pm & 1.8 & 1.330 & 0.188 \\
15 & 1.9 & \pm & 1.3 & 1.1 & \pm & 0.7 & 2.968 & $0.004^{*}$ \\
16 & 2.1 & \pm & 1.4 & 2.5 & \pm & 0.5 & 1.474 & 0.146 \\
17 & 2.2 & \pm & 1.6 & 2.9 & \pm & 0.7 & 2.195 & $0.032^{*}$ \\
18 & 1.5 & \pm & 1.8 & 2.4 & \pm & 0.5 & 2.639 & $0.011^{*}$ \\
19 & 2.7 & \pm & 0.4 & 1.9 & \pm & 0.90 & 4.449 & $<0.001^{*}$ \\
20 & 2.0 & \pm & 0.7 & 2.0 & \pm & 1.09 & 0.000 & 1.000 \\
21 & 1.3 & \pm & 0.4 & 1.4 & \pm & 1.2 & 0.433 & 0.666 \\
22 & 1.8 & \pm & 0.3 & 1.5 & \pm & 1.0 & 1.574 & 0.121 \\
23 & 2.0 & \pm & 0.2 & 2.1 & \pm & 0.4 & 1.225 & 0.225 \\
24 & 2.3 & \pm & 0.5 & 2.1 & \pm & 0.9 & 1.064 & 0.291 \\
\hline
\end{tabular}

$\mathrm{t}$ test

data are presented as mean \pm SD or number

$\mathrm{n}=$ number of patients.

The data of narcotic consumption for the two study groups were recorded indicating that pethidine consumption was statistically significant between the two groups. The mean pethidine consumption over the first 24 hours in milligrams per kg for group A was $2.07 \pm 0.52$ which was less than that for group B which was $2.60 \pm 0.62$ with $p<0.001$.

After investigating the complications of drugs by occurrence of vomiting by the patients of the two study groups during first day post-operative, there was a significant difference between the two study groups, the data was analyzed using chi square test with $P$-value $=0.038$.

Also, the data of regaining of the intestinal movement was recorded by time consumed in hours to regain the intestinal motility, by hearing the intestinal sounds using a stethoscope for abdominal auscultation of the patients every hour post-operative. Then, the data was statistically analyzed using $t$ test. The mean hours post-operative for regaining the intestinal motility in group (A) was $6.72 \pm 1.1$ and for group (B) was $8.36 \pm 1.22$ with $P$-value $<0.001$ which is highly significant statistically.

Also, the time of first dose of pethidine needed as rescue analgesia was recorded and statistically analyzed using $\mathrm{t}$ test, which showed statistical significance. The mean timing by group 1 was $4.33 \pm 0.48$ and that for group 2 was $2.57 \pm 0.68$ with $P$-value $<0.001$ in (Table 4). 
Table 4: Showed timing of need of first rescue analgesia post operative.

\begin{tabular}{|c|c|c|c|c|c|c|c|c|}
\hline \multirow{3}{*}{$\begin{array}{l}\begin{array}{l}\text { Time of first dose } \\
\text { (in hors post operative) }\end{array} \\
\text { Mean } \pm \text { SD }\end{array}$} & \multirow{2}{*}{\multicolumn{3}{|c|}{$\begin{array}{c}\text { Group A } \\
(\mathrm{N}=30)\end{array}$}} & \multirow{2}{*}{\multicolumn{3}{|c|}{$\begin{array}{c}\text { Group B } \\
(\mathrm{N}=30)\end{array}$}} & \multicolumn{2}{|c|}{ T-test } \\
\hline & & & & & & & $\mathrm{t}$ & $P$-value \\
\hline & 4.33 & \pm & 0.48 & 2.57 & \pm & 0.68 & 11.642 & $<0.001^{* *}$ \\
\hline
\end{tabular}

Also, the study recorded the post-operative hospital stay in hours between the two groups. The mean hospital stay in hours for group A was $43.93 \pm 1.17$ and that for group B was $46.20 \pm 1.03$ with $P$-value $<0.001$.

\section{DISCUSSION}

The current study was held at Ain Shams University Maternity Hospital over the period from October 2017 to July 2018 for those women who underwent abdominal hysterectomy. The sixty women were divided into two equal groups, group (A) was given intravenous dose of magnesium sulfate $(50 \mathrm{mg} / \mathrm{kg}$ in $100 \mathrm{~mL}$ of normal saline solution), just 15 minutes post operative at the recovery room, the other group (B) was given $75 \mathrm{mg}$ of diclofenac sodium in 100 $\mathrm{ml}$ of 0.9 sodium chloride solution at the same time post operative, then postoperative pain throughout the first day after the abdominal hysterectomy was assessed using VAS scoring system every hour all over the first 24 hours post operative. Opioid (pethidine) consumption was recorded all over the first 24 hours after the operation.

The current study showed that group (A) which received magnesium sulphate post operative used lesser amount of narcotics specifically pethidine during the first day after abdominal hysterectomy than group (B) which received diclofenac sodium also post operative. There was statistically significant difference between the two groups as the mean amount of pethidine consumption in milligrams $/ \mathrm{kg}+$ SD of group A was $2.07+0.52$ and that of group B was 2.60+_0.62, with $P$-value $<0.001$.

This agreed with the study of Jarahzadeh and his colleagues $^{[6]}$ which was done on 60 patients who had undergone abdominal hysterectomies. The patients were divided randomly into two groups of 30 members each. All of the patients received $5 \mathrm{mg}$ of intravenous morphine 30 min after induction of anesthesia. Afterwards, the study group received $50 \mathrm{mg} / \mathrm{kg}$ of magnesium sulfate in $500 \mathrm{~cm} 3$ of Ringer's solution during the 20 minutes and $500 \mathrm{~cm} 3$ of Ringer's serum was administered to the members of the placebo group. Visual analogue scale VAS scores were evaluated to reach the minimum difference of 0.8 in mean pain score. The results of this study indicated that the mean pain scores immediately after surgery and at $1,2,6$, and 12 $\mathrm{hr}$ after surgery were lower in the study group than in the placebo group. The mean value of narcotic consumption at all measured time points was higher in the placebo group.
No significant differences were found between two groups concerning drug complications ${ }^{[6]}$.

Similar in this latter study, visual analogue scale (VAS) was also used in the current study to assess the analgesic requirement in the postoperative period.

The results showed significant decrease in the mean pain score in the study group indicating the evident effect of magnesium sulfate in postoperative analgesia.

Similarly, in another study conducted by Kahraman and Eroglu $^{[7]}$ on 40 patients who had undergone abdominal hysterectomy surgery under spinal anesthesia, it was shown that pain score and the amount of morphine intake in a group that had received $60 \mathrm{mg} / \mathrm{kg}$ magnesium during surgery was lower compared to the patients in the placebo group, who had received normal saline. However, the type of anesthesia and the dose rate of magnesium sulfate in this study were different.

Similar results were obtained by Ryu and his colleagues ${ }^{[8]}$ in a study done on 60 patients who were candidates for hysterectomy. After the preoperative prescription of $50 \mathrm{mg} /$ $\mathrm{kg}$ of magnesium sulfate and $15 \mathrm{mg} / \mathrm{kg}$ during abdominal hysterectomy surgery, it was seen that the pain score and total rate of morphine use in the magnesium group was remarkably lower than in the placebo group ${ }^{[8]}$.

Another study by Albrecht et al. ${ }^{[4]}$ showed that intravenous magnesium has been reported to improve postoperative pain; however, the evidence was inconsistent. The objective of this quantitative systematic review was to evaluate whether or not the peri-operative administration of intravenous magnesium can reduce postoperative pain Twenty-five trials comparing magnesium with placebo were identified. Independent of the mode of administration (bolus or continuous infusion), peri-operative magnesium reduced the cumulative intravenous morphine consumption by $24.4 \%$ (mean difference: $7.6 \mathrm{mg}$; $\mathrm{p} \quad 95 \% \mathrm{CI}-9.5$ to $-5.8<\mathrm{h}$ postoperatively. Numeric pain 0.00001 ) at $24 \mathrm{~h}$ postoperatively were reduced by $4.2(95 \%$ scores at rest and on movement at $24 \mathrm{CI}-6.3$ to $-2.1 ; \mathrm{p}<0.009)$ out $=0.0001)$ and $9.2(95 \% \mathrm{CI}-16.1$ to $-2.3 ; \mathrm{p}$ of 100 , respectively. We conclude that peri-operative intravenous magnesium reduces opioid consumption and to a lesser extent, pain scores, in the first 24 hours postoperatively without any reported serious adverse effects ${ }^{[4]}$. 
Some studies compared the effect of magnesium sulphate on pain control in other surgeries rather than hysterectomy as Mavrommati and colleagues ${ }^{[9]}$ assessed the infusion of low dose $\mathrm{Mg}$ sulfate in hernioplasty and concluded that preventive lower bolus doses of $\mathrm{Mg}$ sulfate are an effective adjuvant for perioperative analgesic management.

Similar results were obtained by Dabbagh and his colleagues $^{[10]}$ on 60 patients underwent lower extremity orthopedic surgery under spinal anesthesia; the pain score 12 hours after surgery and the amount of morphine consumption in the first 24 hours after surgery in a group of patients who received $8 \mathrm{mg} / \mathrm{kg}$ of magnesium sulfate before surgery was lower than the placebo group (normal saline).

On the contrary after reviewing the literature, WilderSmith and colleagues ${ }^{[11]}$ used a perioperative infusion of magnesium levulinate in patients undergoing elective TAH and concluded that preoperative magnesium infusion does not improve postoperative analgesia. A small study group size and inadequate dose of magnesium might have been possible causes of this finding.

Supporting the later point of view Lysakowski and colleagues ${ }^{[12]}$ in a systemic review randomized trial reached different conclusions related to this study as their trials do not provide convincing evidence that perioperative $\mathrm{Mg}$ has favorable effects on postoperative pain intensity and analgesic requirement.

Compared to all the previously discussed studies, in the current study magnesium sulfate and diclofenac were only used in the postoperative period after complete recovery of the patient from general anesthesia.

So, the results are obtained by comparing the effect of magnesium sulfate and diclofenac separated from the possible interference of anesthetic agents.

Regarding the regaining of intestinal motility post operative, at the current study which reached that the mean hours post operative for regaining the intestinal motility in group(A) was $6.72 \pm 1.1$ and for group (B) was $8.36 \pm 1.22$ with $P$-value $<0.001$ which is highly significant statistically.

By confirmation of the effect of magnesium on sympathetic effects including the results of several studies on decreasing systemic vascular resistance (SVR); Moharari et al. proved that magnesium may be effective on decreasing postoperative ileus in major abdominal surgery.

Regarding the hypotensive effect of $\mathrm{Mg}$ which is explained by its direct vasodilating effect through the calcium channel blockade, it was rarely observed with magnesium sulphate up to $60 \mathrm{mg} / \mathrm{kg}^{[13]}$.

In the recent study, hypotensive effect of $\mathrm{Mg}$ sulfate has not been seen because the dose which was used by our study as $(50 \mathrm{mg} / \mathrm{kg})$ is very low to do such an effect. On the other hand, 20\% increasing in MAP and HR or pain according to numerical rating system $(\mathrm{NRS})>3$ were the indication of Pethidine administration. Throughout the first 24 hours after the surgeries, NRS was lower in Mg sulfate group compared to the control one significantly. Indeed, because for low doses of $\mathrm{Mg}$, it did not intensify the action of neuromuscular depolarizing muscle blockers. Unfortunately, we did not measure ionized $\mathrm{Mg}$ level for some instrument restrictions but measured total serum $\mathrm{Mg}$ level instead. According to the results, there was not any evidence of nausea and vomiting, hypotension or hypermagnesemia. So, we found that preventive doses of $\mathrm{Mg}$ sulfate could be useful as an adjuvant drug for TAH under balanced general anesthesia.

\section{CONCLUSION}

We concluded that IV preventive doses (low doses) of magnesium sulphate with dosage of $50 \mathrm{mg} / \mathrm{kg}$ in $100 \mathrm{~mL}$ of normal saline solution alleviate postoperative pain throughout the first day after TAH under balanced general anesthesia significantly and reduce opioid consumption as well.

\section{CONFLICT OF INTEREST}

There are no conflicts of interest.

\section{REFERENCES}

1. Duhan N and Sirohiwai D. Uterine myomas revisited. Eur J Obstet Gynecol Reprod Biol. 2010; 152:119-125.

2. Perniola A, Gupta A, Crafoord K, Darvish B, Magnuson A, Axelsson K. Intraabdominal local anaesthetics for postoperative pain relief following abdominal hysterectomy: a randomized, doubleblind, dose-finding study, Eur J Anaesthesiol, 2009; 26: 421-9.

3. Recart A, Duchene D, White PF, Thomas T, Johnson DB, Cadeddu JA. Efficacy and safety of fast-track recovery strategy for patients undergoing laparoscopic nephrectomy. Journal of Endourology, 2005; 19(10): 1165-1169.

4. Albrecht E, Kirkham KR, Liu SS, Brull R. Perioperative intravenous administration of magnesium sulphate and postoperative pain: a meta-analysis. Anaesthesia, 2013; 68:79-90.

5. Haryalchi K, Ghanaie MM, Yaghoubi Y, Milani F, Faraji R. An assessment of changes in the magnesium level during gynecological abdominal surgeries. Journal of Basic and Clinical Reproductive Sciences, 2013; 2(2): 110-114. 
6. Jarahzadeh MH, Harati ST, Babaeizadeh H, Yasaei E, Bashar FR. The effect of intravenous magnesium sulfate infusion on reduction of pain after abdominal hysterectomy under general anesthesia: a doubleblind, randomized clinical trial. Electronic physician. 2016; 8(7):2602.

7. Kahraman F and Eroglu A. The effect of intravenous magnesium sulfate infusion on sensory spinal block and postoperative pain score in abdominal hysterectomy. Biomed Res Int. 2014;2014:236024.

8. Ryu JH, Kang MH, Park KS, Do SH. "Effects of magnesium sulphate on intraoperative anaesthetic requirements and postoperative analgesia in gynaecology patients receiving total intravenous anaesthesia," British Journal of Anaesthesia, 2008; 100(3): 397-403.

9. Mavrommati PD, Gabopoulou ZT, Papadimos CN, et al. The perioperative infusion of low doses of magnesium sulfate reduces analgesic requirements in patients undergoing abdominal hernioplasty," Acute Pain, 2004; 5(3-4): 81-87.

10. Dabbagh A, Elyasi H, Razavi SS, Fathi M, Rajaei S. Intravenous magnesium sulfate for postoperative pain in patients undergoing lower limb orthopedic surgery. Acta Anaesthesiol Scand. 2009; 53(8):1088-91.

11. Wilder-Smith $\mathrm{CH}$, Knöpfli R, Wilder-Smith G. "Perioperative magnesium infusion and postoperative pain," Acta Anaesthesiologica Scandinavica, 1997; 41(8): 1023-1027.

12. Lysakowski C, Dumont L, Czarnetzki C, MR Tramèr C. "Magnesium as an adjuvant to postoperative analgesia: a systematic review of randomized trials," Anesthesia and Analgesia, 2007; 104(6): 1532-1539.

13. Miller RD. Miller's Anesthesia, vol. 31, Churchil Livingstone, San Diego, Calif, USA, $8^{\text {th }}$ edition, 2015. 